Check for updates

Cite this: RSC Adv., 2018, 8, 16927

Received 8th April 2018

Accepted 2nd May 2018

DOI: $10.1039 / c 8 r a 03016 b$

rsc.li/rsc-advances

\section{Recrystallization techniques for the synthesis of ZnO nanorods: an in situ process for carbon doping and enhancing the dispersion concentration of $\mathrm{ZnO}$ nanorods $\uparrow$}

\author{
Muhammad Mohsin Hossain, (DD ${ }^{a}$ Md. Akherul Islam, ${ }^{b}$ Hossain Shima, ${ }^{c}$ \\ Mudassir Hasan, ${ }^{d}$ Muhammad Hilal (D) ${ }^{e}$ and Moonyong Lee ${ }^{\star f}$
}

Zinc acetate is recrystallized as lumber-shaped tetragonal rods by a novel recrystallization technique. Subsequently, the recrystallized zinc acetate is converted into $\mathrm{ZnO}$ nanorods in a glass vial by the simplest and cheapest method without utilizing any expensive instrumentation. Carbon is doped in $\mathrm{ZnO}$ nanorods during the preparation $\mathrm{ZnO}$ nanorods without any extra steps, chemicals, or effort. The carbon-doped $\mathrm{ZnO}$ nanorods can be dispersed in a solvent at very high concentrations and are also stable for a very long time, which are comparatively higher than those of the other existing $\mathrm{ZnO}$ nanoparticles. The higher dispersion concentration and higher stability of $\mathrm{ZnO}$ nanoparticles are explained by a scheme that demonstrates the suspending mechanism of the $\mathrm{ZnO}$ nanoparticles at higher concentrations with higher stabilities in a solvent through the anchoring groups of carbon. No materials are used for surface modification; no surface coatings, ionic materials, or $\mathrm{pH}$ controlling materials are used to increase the dispersion concentration and stability. This is the first observation of the doped carbon playing a significant role in the dispersion of $\mathrm{ZnO}$ nanoparticles at higher concentrations by withholding them in the solvent. Therefore, doped carbon at the surface of $\mathrm{ZnO}$ nanoparticles prevents the self-aggregation of $\mathrm{ZnO}$ nanoparticles in the solution phase by interfacial barrier layers among $\mathrm{ZnO}$ nanorods and interfacial interactive layer between $\mathrm{ZnO}$ nanorod and solvent.

\section{Introduction}

Nanoparticles and their high-concentration dispersion are very important for many applications. ${ }^{1}$ For example, the high dispersion of $\mathrm{ZnO}$ nanoparticles can be used in oil recovery or oil separation, ${ }^{2}$ coolants, heat transfer, ${ }^{3}$ strong blue emission ${ }^{4-7}$ photoluminescence, ${ }^{8}$ beautification products, textiles, coatings, paints, as fillers for composite materials, in optoelectronic applications, ${ }^{9}$ water splitting, ${ }^{\mathbf{1 0 , 1 1}}$ photoanodes and photocatalysis, ${ }^{11}$ and organic molecule synthesis. ${ }^{12}$

${ }^{a}$ Department of Energy and Materials Engineering, Dongguk University, Seoul 04620, Republic of Korea $712-749$

${ }^{b}$ Department of Pharmacy, Atish Dipankar University of Science \& Technology, Banani, Dhaka 1213, Bangladesh

'Department of Chemistry, Rajshahi Univesity, Rajshahi 6205, Bangladesh

${ }^{d}$ Department of Chemical Engineering, King Khalid University, Abha 61411, Kingdom of Saudi Arabia

${ }^{e}$ Ghulam Ishaq Khan Institute of Engineering Sciences and Technology, Topi, Khyber Pakhtunkhwa, Pakistan

${ }^{f}$ School of Chemical Engineering, Yeungnam University, Gyeongsan 712-749, Republic of Korea

$\dagger$ Electronic supplementary information (ESI) available. See DOI: $10.1039 / \mathrm{c} 8 \mathrm{ra03016b}$
However, for different types of device formation and applications, the nanoparticles should be dispersed homogeneously in the liquid phase with good stability. Subsequently, this homogeneous stable solution of $\mathrm{ZnO}$ nanoparticles can be used for painting, coating, textiles, skin beautification, heat transfer, blue emission, and optoelectronic applications. However, if nanoparticles are not dispersed homogeneously, they create aggregations in the thin film device surface, composite matrix, other substrates, or solution. Generally, this disadvantage is due to the high surface energy of the nanoparticles, which causes their agglomeration. ${ }^{\mathbf{1 3}}$ Consequently, such nanoparticles are not stable in aqueous media during storage. ${ }^{14}$

Several methods have been utilized to prevent such aggregation and produce stable $\mathrm{ZnO}$ nanoparticles, including covering $\mathrm{ZnO}$ nanoparticles by organic molecules ${ }^{15-17}$ or inorganic $\mathrm{SiO}_{2}$ shells ${ }^{18}$ and coating ${ }^{19}$ the nanoparticle surface by polymerization. Alternatively, other efforts have been undertaken to improve the dispersion stability of $\mathrm{ZnO}$ in an organic solvent or in the aqueous phase by using a surfactant, ${ }^{20}$ polymer $^{\mathbf{8 , 2 1 , 2 2}}$ phosphate, ${ }^{23}$ inositol hexakisphosphate, ${ }^{24}$ organic matter, ${ }^{25-27}$ or oleic acid, ${ }^{6,28}$ a combination of a polymer and exfoliating agent such as zirconium phosphate ${ }^{29}$ ionic materials $;^{30}$ and the controlled combined effect ${ }^{31}$ of $\mathrm{pH}$ and ionic 
strength. However, surface modification has a significant impact on various properties; $;^{\mathbf{4 , 5}}$ further, it is useful to obtain a stable $\mathrm{ZnO}$ solution that allows the dispersion of $\mathrm{ZnO}$ nanoparticles in organic and water ${ }^{7}$ solvents.

However, the concentration of $\mathrm{ZnO}$ nanoparticles had not been mentioned in most studies. ${ }^{6,21-25,31}$ Without the optimum concentration of $\mathrm{ZnO}$ nanoparticles, the stability of $\mathrm{ZnO}$ nanoparticles cannot be guaranteed, because the stability directly depends of the concentration of $\mathrm{ZnO}$ nanoparticles. If a higher concentration is used, $\mathrm{ZnO}$ will be aggregated quickly and if a lower concentration is used, a higher stability is shown. Therefore, the dispersion concentration is very important to show the dispersion stability of ZnO nanoparticles. Nevertheless, most previous studies have excluded the concentration of ZnO nanoparticles. The researchers in previous works have used lower initial concentrations of $\mathrm{ZnO}$ nanoparticles to show the long-time stability of $\mathrm{ZnO}$ nanoparticles in solution. However, it is not significant to understand actual stability of $\mathrm{ZnO}$ nanoparticles because of the lower concentration of $\mathrm{ZnO}$. Additionally, a lower concentration is not ideal for applications. Anyway, previous studies have demonstrated dispersion concentrations of $0.02 \mathrm{mg} \mathrm{mL} \mathrm{m}^{-1},{ }^{3} 0.001 \mathrm{mg} \mathrm{mL}^{-1},{ }^{20} 0.01 \mathrm{mg}$ $\mathrm{mL}^{-1},^{26} 0.02 \mathrm{mg} \mathrm{mL}^{-1},{ }^{29} 0.05-0.10 \mathrm{mg} \mathrm{mL}^{-1},{ }^{30} 0.01 \mathrm{mg} \mathrm{mL}^{-1},{ }^{27}$ $0.01 \mathrm{mg} \mathrm{mL}^{-1},{ }^{32}$ and 0.2 and $\mathrm{mg} \mathrm{mL} \mathrm{m}^{-1},{ }^{8}$ which are very low.

The most fruitful method to prepare $\mathrm{ZnO}$ nanoparticles is the sol-gel route. ${ }^{33}$ This method well dispersed $\mathrm{ZnO}$ nanoparticles using simple ultrasound but the dispersion concentration $\left(0.08 \mathrm{mg} \mathrm{mL}^{-1}\right)$ was lower. For the case of polymer coating or polymer functionalization on $\mathrm{ZnO}$ nanoparticles surface, the synthesized polymer increases the viscosity of the solution or $\mathrm{ZnO}$ medium. Therefore, the sedimentation of $\mathrm{ZnO}$ nanoparticles in the polymer matrix or in the polymer solution decreases. In fact, this is due to suspending $\mathrm{ZnO}$ nanoparticles by increasing the viscosity of the medium. Therefore, this process is only applicable for specific applications because of the limitation of the separation techniques of $\mathrm{ZnO}$ nanoparticles from a polymer solution or from the surface-deposited polymer matrix. Thus, these techniques are not feasible for a wide range of applications. For the other cases above, third materials (surfactant, organic matters, phosphate, inositol hexakisphosphate, zirconium phosphate, ionic materials, oleic acid, etc.) are used for improving the dispersion stability; however, this resulted in a longer, more complex, and more expensive synthesis.

Recently, dispersion concentration has been improved by the interaction of $\mathrm{Zn}$ in $\mathrm{ZnO}$ nanoparticles with $\mathrm{CO}_{2},{ }^{9}$ which is very interesting work. By this process, the improvement in dispersion concentration occurred from $0.001 \mathrm{mg} \mathrm{mL}^{-1}$ to $0.02 \mathrm{mg} \mathrm{mL}^{-1}$; however, the final dispersion concentration was very low $\left(0.02 \mathrm{mg} \mathrm{mL} \mathrm{m}^{-1}\right)$. Therefore, a flexible process that allows for the smooth synthesis of highly dispersible and higher stability ZnO nanoparticles is required.

Here, we synthesized $\mathrm{ZnO}$ nanoparticles by a novel recrystallization technique in which a cheap and easy process was utilized. The unique recrystallization technique can synthesize a large amount of $\mathrm{ZnO}$ nanoparticles without utilizing any expensive instrumentation. In addition, this process permits in situ carbon doping in ZnO nanorods without any extra steps, chemicals, or effort. The prepared carbon-doped $\mathrm{ZnO}$ nanoparticles showed significantly higher dispersion concentration and higher stability than the existing research works. The doped carbon inside the ZnO nanoparticles bonded chemically with $\mathrm{Zn}$ and functioned as anchoring groups through its functional groups with the solvent at interface. Therefore, the $\mathrm{ZnO}$ nanoparticles were suspended well in the solution and the dispersion concentration and stability were increased. Finally, the mechanism of dispersion improvement is shown to explain the role of doped carbon as an anchor to suspend $\mathrm{ZnO}$ nanoparticles in liquid media.

\section{Experimental}

\subsection{Instrumentation}

The structural morphology of the $\mathrm{ZnO}$ nanorods was determined using field-emission scanning electron microscopy (FESEM, S-4800, Hitachi, Japan) and transmission electron microscopy (FE-TEM, TECHNAI G2 F2O S-TWIN, FEI Company, USA). Crystallographic information was acquired using X-ray diffraction (XRD, thin film, MPD, PANalytical). The vibrational phonon modes of the nanorods were described by Raman spectroscopy (HORIBA JOBIN YVON, Lab RAM HR, laser wavelength 514.54). X-ray photoelectron spectroscopy (XPS, K-Alpha, Thermo Scientific, USA) was utilized to determine the binding character of $\mathrm{ZnO}$ nanorods and carbon, where the latter was doped in $\mathrm{ZnO}$ nanorods.

\subsection{Chemicals}

Zinc acetate dihydrate (Sigma Aldrich, 98\%) was dissolved in ethanol (95\%, Duksan, Korea) and sonicated to prepare the solution of zinc acetate $\left(60 \mathrm{mg} \mathrm{mL}^{-1}\right)$. The recrystallized zinc acetate was prepared from the zinc acetate solution by a longtime settlement. $\mathrm{ZnO}$ nanorods were synthesized from the recrystallized zinc acetate.

\subsection{Preparation process of $\mathrm{ZnO}$ nanorods}

Zinc acetate dihydrate $(4.8 \mathrm{~g})$ was added to ethanol $(80 \mathrm{~mL})$ to prepare $60 \mathrm{mg} \mathrm{mL}^{-1}$ solution of zinc acetate. The solution was sonicated in a glass bottle around 70 min until a clear homogeneous solution was obtained. Subsequently, it was allowed to settle for $12 \mathrm{~h}$ so that the compound recrystallized at the bottom of the glass bottle. Then, the clear ethanol was discarded from the bottle, and the recrystallized zinc acetate was collected. Some of this zinc acetate was placed in an empty glass vial (10 $\mathrm{mL}$ ) and heated at $450{ }^{\circ} \mathrm{C}$ for $45 \mathrm{~min}$ to prepare the $\mathrm{ZnO}$ nanorods.

\section{Results and discussion}

\subsection{ZnO and HT ZnO nanorods}

Fig. 1a shows the optical image of the recrystallized zinc acetate at the bottom side of the glass bottle. To clearly show the recrystallized zinc acetate, a high-resolution image is shown in Fig. 1b and the bottle top side was turned down 

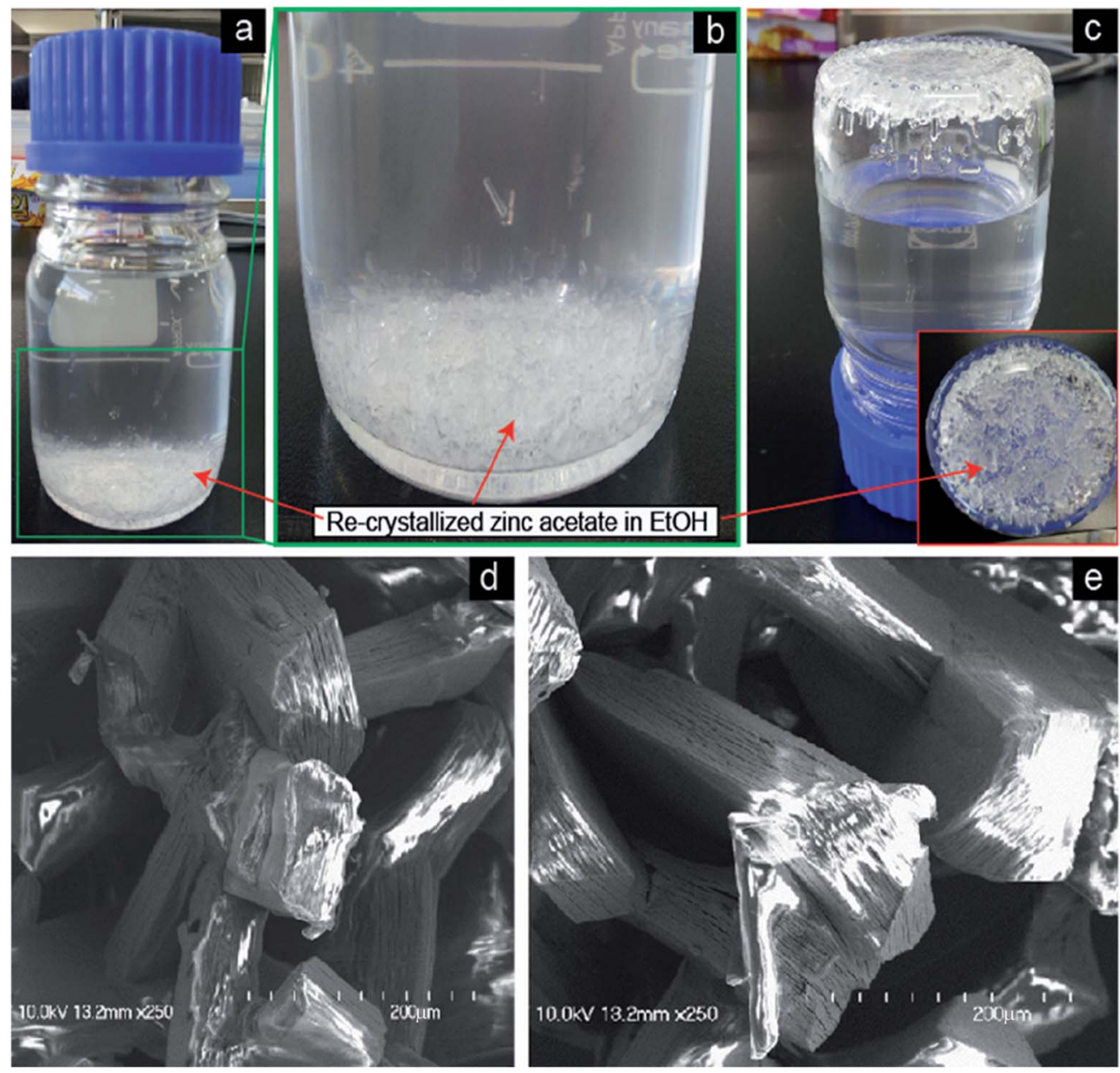

Fig. 1 Recrystallized zinc acetate photograph and FESEM images. (a) Recrystallized zinc acetate in ethanol solution, (b and c) high resolution of the bottom part of the bottle was shown to show the clear crystal of zinc acetate, and ( $d$ and e) FESEM images of recrystallized zinc acetate.

(Fig. 1c). FESEM images (Fig. 1d and e) of the recrystallized zinc acetate were obtained to investigate the surface morphology of the recrystallized zinc acetate. Fig. 1d and e indicate the chopped-wood structure. Further, $500 \mathrm{mg}$ of the recrystallized zinc acetate was heated in a glass vial $(10 \mathrm{~mL})$ to prepare $\mathrm{ZnO}$ nanorods at $450{ }^{\circ} \mathrm{C}$ for $45 \mathrm{~min}$. FESEM images (Fig. 2) of the prepared $\mathrm{ZnO}$ nanorods were obtained. Fig. 2a shows the ZnO nanorods pile. Step-by-step high-resolution FESEM images (Fig. 2b-e) show the rod-shaped $\mathrm{ZnO}$ nanoparticles. Fig. 2e is obtained from the marked area of Fig. 2d; Fig. $2 \mathrm{~d}$ is obtained from the rectangular area of Fig. 2c; Fig. 2c is shown from the rectangular marked area of Fig. 2b; finally, Fig. $2 b$ is exhibited from the marked area of Fig. 2a. Fig. 2e exhibited the rod-shaped structure. Clear nanorod-shaped structures are shown in Fig. 2f. Based on Fig. 1 and 2, the $\mathrm{ZnO}$ nanorods preparation schematic diagram is as shown in Fig. 3. Fig. 3a shows the recrystallized zinc acetate that was converted to $\mathrm{ZnO}$ nanorods at $450^{\circ} \mathrm{C}$ (Fig. 3b). The TEM image of the $\mathrm{ZnO}$ nanorods is shown in Fig. 4a. Here, ZnO nanorods were clearly observed. The high-resolution TEM image (Fig. 4b) shows the crystalline phase of the $\mathrm{ZnO}$ nanorods, which are more visible in Fig. 4c. The latter is obtained from the marked area of Fig. $4 \mathrm{~b}$. It shows the (002) plane with $0.26 \AA$ of the $\mathrm{ZnO}$ nanorods. The selected-area electron diffraction pattern of $\mathrm{ZnO}$ nanorods is shown in Fig. $4 \mathrm{~d}$.

The XRD spectrum (Fig. 5a) shows peaks at 31.0, 33.7, 35.5, $46.8,55.8,62.2,65.7,67.3,68.4,71.9,76.3,80.8$, and 89.0, which are correspond to the (100), (002), (101), (102), (110), (103), (200), (112), (201), (004), (202), (104), and (203) planes, respectively. The peak positions and their corresponding planes suggest the wurtzite structure of $\mathrm{ZnO}$ nanorods with JCPDS no. 01-075-0576. ..$^{34-38}$ The high-intensity (101)-plane peak at 35.5 indicated that the nanorods were selectively oriented to the (101) plane. The 2-30 $(2 \theta)$ area was magnified

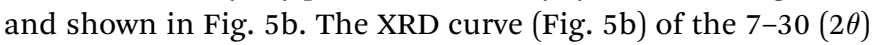
area indicated a broad band peak of the (002) plane. It is the characteristic peak of carbon at position $22.75 .^{37,39-41}$ This broad band carbon peak suggests that low-crystalline carbon is present in the $\mathrm{ZnO}$ nanorods. The formation of low-crystalline carbon inside the $\mathrm{ZnO}$ nanorods may have occurred during the decomposition of recrystallized zinc acetate $450{ }^{\circ} \mathrm{C}$ for $45 \mathrm{~min}$. However, the XRD spectrum indicates that carbon is present inside the $\mathrm{ZnO}$ nanorods. 

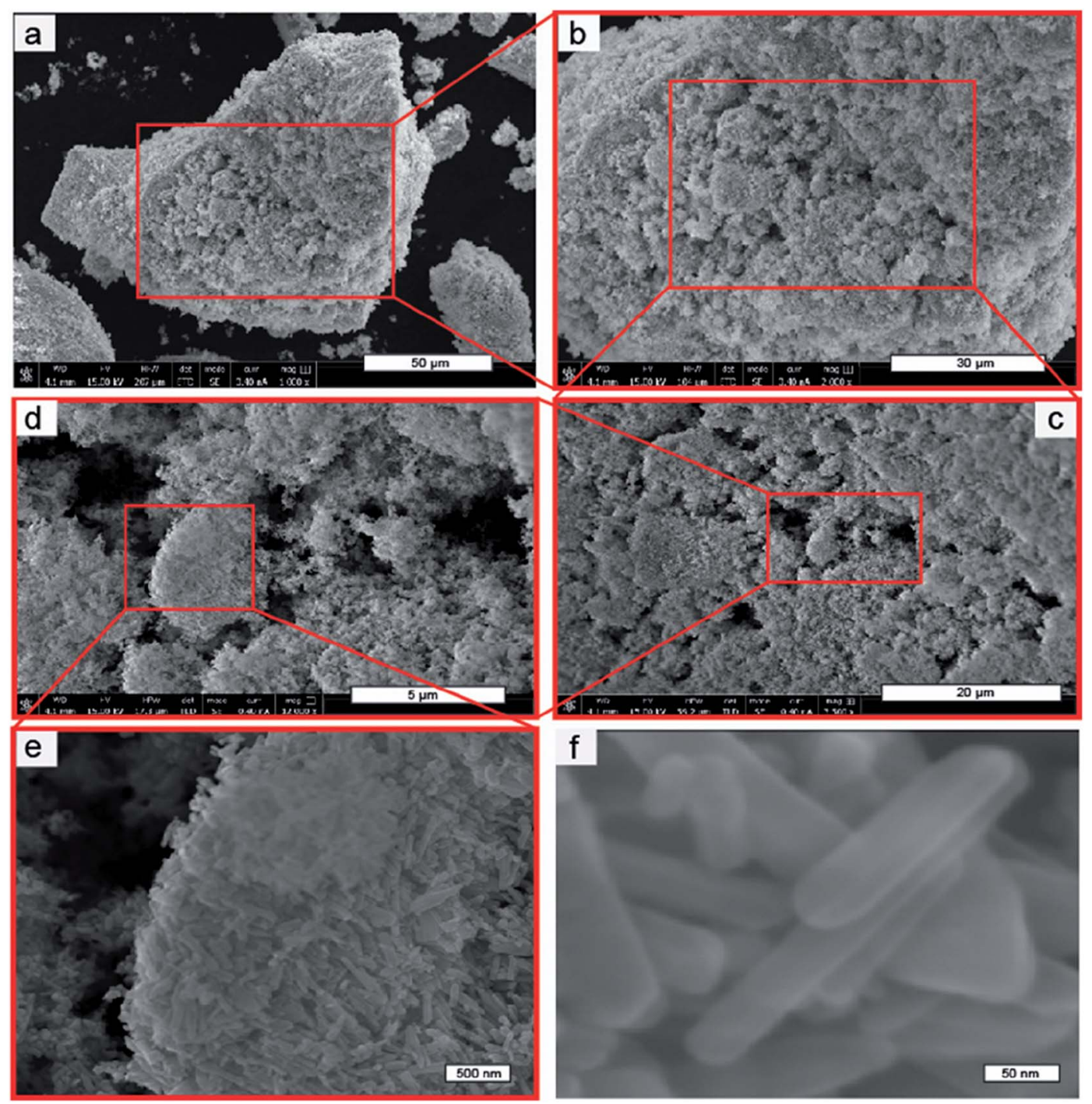

Fig. 2 FEFSEM images of ZnO nanorods. (a) Low resolution of FESEM image of ZnO nanorods stack, (b) ZnO nanorods FESEM image was taken from the rectangular area of (a), (c) comparatively high resolution FESEM image of ZnO nanorods was taken from the rectangular area of (b), (d) comparatively more high resolution FESEM image of $\mathrm{ZnO}$ nanorods was taken from the rectangular area of (c), (e) high resolution FESEM image of $\mathrm{ZnO}$ nanorods was taken from the square marked area of (d), and (f) here more high resolution FESEM image of ZnO nanorods was shown.

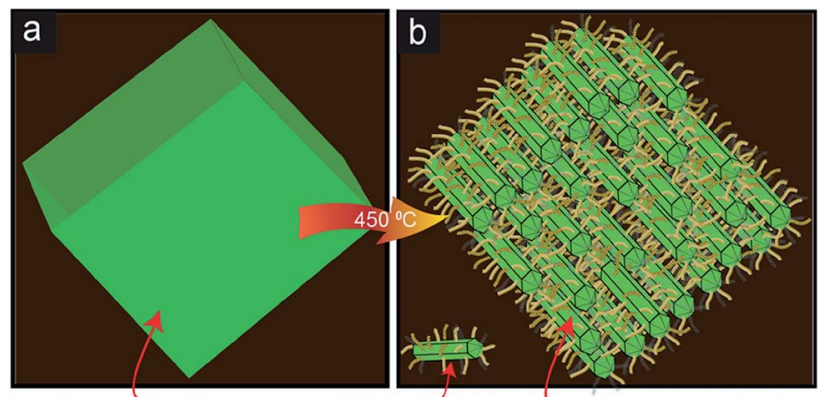

Recrystallized Zinc acetate ZnO nanorods Zno nanorods stacks

Fig. 3 Schematic diagram of the ZnO nanorods from zinc acetate recrystal. (a) Re-crystallized zinc acetate and (b) ZnO nanorods prepared from the zinc acetate re-crystal.

\subsection{Raman spectrum to determine the carbon and its} character inside the $\mathrm{ZnO}$ nanorods

Raman spectroscopy (Fig. S1†) analysis of ZnO was performed to investigate the interactions of the $\mathrm{ZnO}$ nanorods containing carbon. Fig. S1† exhibits the Raman spectra at $50-1700 \mathrm{~cm}^{-1}$, showing peaks at 94.4, 221.2, 325.5, 378.0, 432.7, 570.0, 1145.0, and $1578.5 \mathrm{~cm}^{-1}$. The peak at $221.2 \mathrm{~cm}^{-1}$ was assigned to the 2$\mathrm{E}_{2}(\mathrm{M})$ phonon mode of the $\mathrm{ZnO}$ nanorod, which is the secondorder Raman spectrum due to the zone boundary ( $M$ point). ${ }^{\mathbf{4 1}}$ The peak at $378.0 \mathrm{~cm}^{-1}$ was related to the $\mathrm{A}_{1}$ phonon vibration mode to the transverse optical (TO) direction of the $\mathrm{ZnO}$ nanorods. ${ }^{42}$ The peaks at positions $94.4 \mathrm{~cm}^{-1}$ and $432.7 \mathrm{~cm}^{-1}$ of the $\mathrm{ZnO}$ nanorods were allotted to the $\mathrm{E}_{2}$ (low) ${ }^{\mathbf{4 3}}$ and $\mathrm{E}_{2}$ (high) ${ }^{\mathbf{4 4}}$ phonon, respectively. The peak at $570.0 \mathrm{~cm}^{-1}$ for $\mathrm{ZnO}$ was allotted to the $\mathrm{A}_{1}$ - $\mathrm{LO}$ (longitudinal optical) ${ }^{\mathbf{4 3 , 4 5}}$ phonon mode of $\mathrm{ZnO}$, which is a lower-frequency position than that of the 

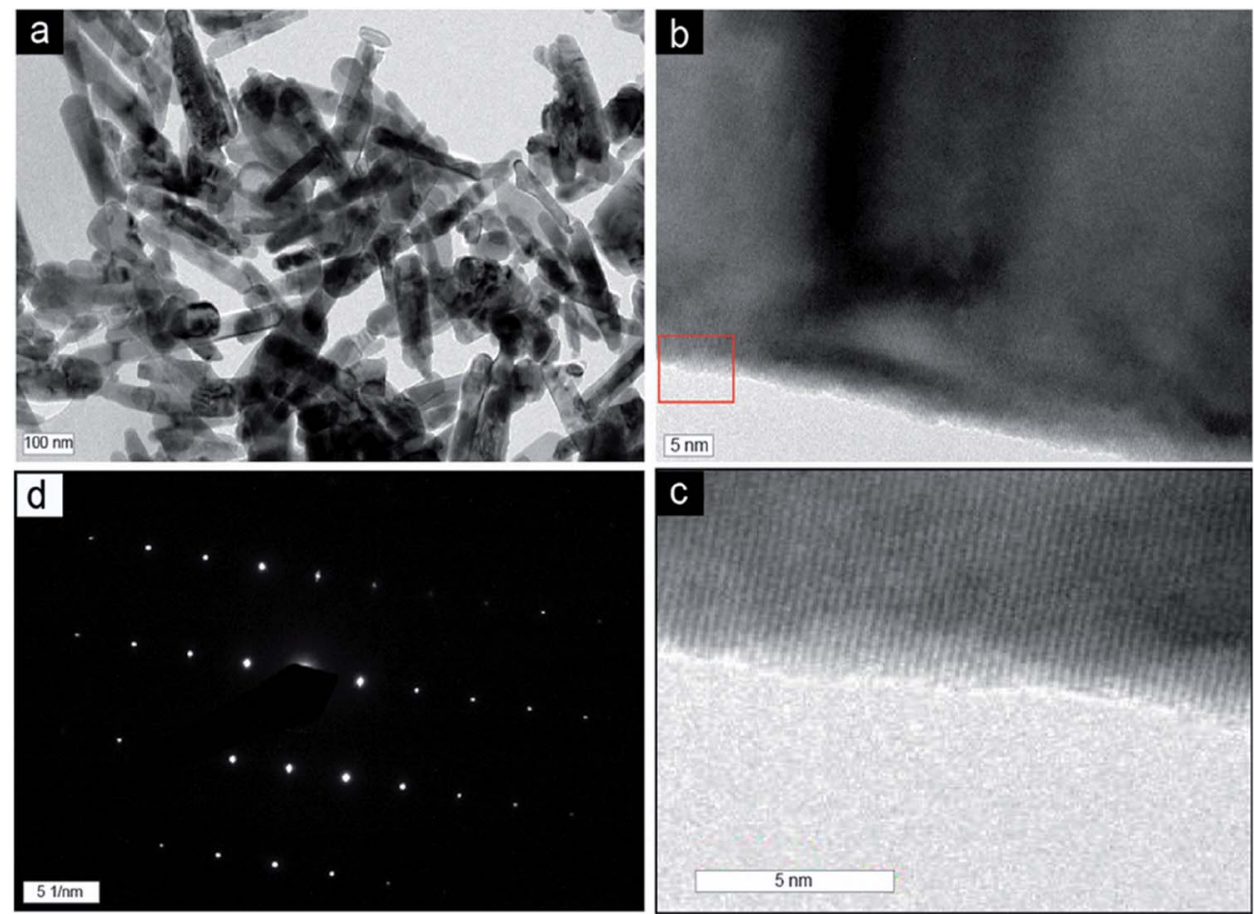

Fig. 4 TEM images of $\mathrm{ZnO}$ nanorods. (a) TEM image of $\mathrm{ZnO}$ nanorods, (b) HRTEM image of ZnO nanorods, (c) more high resolution images was taken from rectangular area of (b), and (d) selected area diffraction of pattern of ZnO nanorods.

normal position (574-579 $\left.\mathrm{cm}^{-1}\right){ }^{43,45-47}$ Therefore, the position of the lower frequency $\left(570.0 \mathrm{~cm}^{-1}\right) \mathrm{A}_{1}$-LO phonon mode also indicated the strong interfacial interaction between the carbon and the $\mathrm{Zn}$ in the $\mathrm{ZnO}$ nanorods. The carbon doping in $\mathrm{ZnO}$ might have decreased the vibrational frequency of $\mathrm{Zn}-\mathrm{O}$ at the longitudinal direction during the incident $514 \mathrm{~nm}$ laser on the ZnO nanorods. The $325 \mathrm{~cm}^{-1}$ peak is for the second-order mode of multiple phonon scattering. The $1145 \mathrm{~cm}^{-1}$ phonon mode is for the Raman peak of the tetrahedral amorphous $\mathrm{sp}^{3}$ carbon, which is generated by the visible excitation ( $514 \mathrm{~nm}$ laser) with a G band at $1578.5 \mathrm{~cm}^{-1}$. ${ }^{48}$ Therefore, the Raman spectra indicated that carbon is present inside the $\mathrm{ZnO}$ nanorods and that it has good interactions with Zn. Additionally, the $1145 \mathrm{~cm}^{-1}$ peak indicates a tetrahedral-type $\left(\mathrm{sp}^{3}\right)$ carbon.

\subsection{XPS analysis to confirm the existence of carbon phase}

The $2 p_{3 / 2}$ and $2 p_{1 / 2}$ peaks (Fig. 6a) at positions $1022 \mathrm{eV}$ and $1045 \mathrm{eV}$, respectively, specify $\mathrm{Zn}$ as $\mathrm{ZnO}$. The interaction of the carbon-containing functional group with $\mathrm{Zn}$ in the $\mathrm{ZnO}$ nanorods is shown by the $\mathrm{O} 1 \mathrm{~s}$ core level peak in Fig. $6 \mathrm{~b}$, which is split into 530.40, 531.10, 532.21, 533.21, and 533.91 eV. The $530.40 \mathrm{eV}$ peak of $\mathrm{O}^{2-}$ shows a wurtzite structure of the $\mathrm{ZnO}$. Two peaks occurred at positions $531.10 \mathrm{eV}$ and $532.21 \mathrm{eV}$, which were generated in the oxygen deficiency region in the $\mathrm{ZnO}$ matrix. ${ }^{49}$ The two oxygen deficiency peaks reveal two different oxygen vacancy environments, which were created owing to the environments of different electronegativities. The $\mathrm{C}-\mathrm{Zn}-\mathrm{C}$ and -O-Zn-C environments might have been available. Between the two environments of $\mathrm{Zn}$ above, $-\mathrm{O}-\mathrm{Zn}-\mathrm{C}$ is more electronegative than $\mathrm{C}-\mathrm{Zn}-\mathrm{C}$. Therefore, the $\mathrm{C}-\mathrm{Zn}-\mathrm{C}$ environment is for the $531.10 \mathrm{eV}$ peak and $-\mathrm{O}-\mathrm{Zn}-\mathrm{C}$ is for the $532.21 \mathrm{eV}$ peak. The $533.21 \mathrm{eV}$ and $533.91 \mathrm{eV}$ peaks are associated to the $\mathrm{C}=\mathrm{O}$ and $\mathrm{C}-\mathrm{O}$ functional groups, respectively, which were attached chemically to $\mathrm{Zn}$ in the $\mathrm{ZnO}$ nanorods matrix. ${ }^{\mathbf{5 0 , 5 1}}$ In general, the peaks are shifted to higher binding energy positions owing to the higher electronegativity. ${ }^{52,53}$ Therefore, the higher electronegative oxygen environment played a significant role in creating the two peaks above in higher binding energy positions. As the $\mathrm{C}=\mathrm{O}$ and $\mathrm{C}-\mathrm{O}$ functional groups were connected to $\mathrm{Zn}, \mathrm{O}=\mathrm{C}-\mathrm{O}-\mathrm{Zn}-\mathrm{O}-\mathrm{C}=\mathrm{O}$ and $\mathrm{C}-\mathrm{O}-\mathrm{Zn}-\mathrm{O}-\mathrm{C}$ features might be available. The $\mathrm{O}=\mathrm{C}-\mathrm{O}-\mathrm{Zn}-\mathrm{O}-\mathrm{C}=\mathrm{O}$ and $\mathrm{C}-\mathrm{O}-\mathrm{Zn}-\mathrm{O}-\mathrm{C}$ motif features are related to the $\mathrm{C}=\mathrm{O}$ and $\mathrm{C}-\mathrm{O}$ functional groups, respectively.

The deconvolution of the $\mathrm{C} 1 \mathrm{~s}$ curve (Fig. 6c) showed peaks at $285.10,285.84,286.39,286.96,287.54,288.47,288.89$, 289.57 , and $290.01 \mathrm{eV}$. A high number of deconvoluted peak in the area of $285 \mathrm{eV}$ to $290 \mathrm{eV}$ suggested that the carbon $\left(\mathrm{sp}^{2}\right)$ inside the $\mathrm{ZnO}$ nanorods were highly functionalized. For example, the binding energies 285.10, 285.84, 286.39, and $286.96 \mathrm{eV}$ were associated with the bond of $\mathrm{C}=\mathrm{C}\left(\mathrm{sp}^{2}\right), \mathrm{C}-\mathrm{C}$ $\left(\mathrm{sp}^{3}\right), \mathrm{C}-\mathrm{O}-\mathrm{C}$, and $\mathrm{C}=\mathrm{O}$, respectively. ${ }^{54}$ The $\pi$ electrons transition $\left(\pi-\pi^{*}\right)$ of $\mathrm{sp}^{2}$ carbon of the $\mathrm{C}=\mathrm{C}$ system here was exhibited at the binding energy of $290.1 \mathrm{eV}$. The peaks at the binding energies of $287.54 \mathrm{eV}$ and $288.47 \mathrm{eV}$ were generated owing to the interaction of $\mathrm{Zn}$ with the $\mathrm{C}-\mathrm{O}-\mathrm{C}$ system. Here, $\mathrm{Zn}$ might have interacted with $\mathrm{C}-\mathrm{O}-\mathrm{C}$ and formed $\mathrm{Zn}-\mathrm{C}-\mathrm{O}-$ $\mathrm{C}-\mathrm{Zn}$ for the $287.54 \mathrm{eV}$ peak, and formed $\mathrm{Zn}-\mathrm{O}-\mathrm{C}-\mathrm{O}-\mathrm{C}-\mathrm{O}-\mathrm{Zn}$ for $288.47 \mathrm{eV}$. Similarly, the other two peaks at binding 

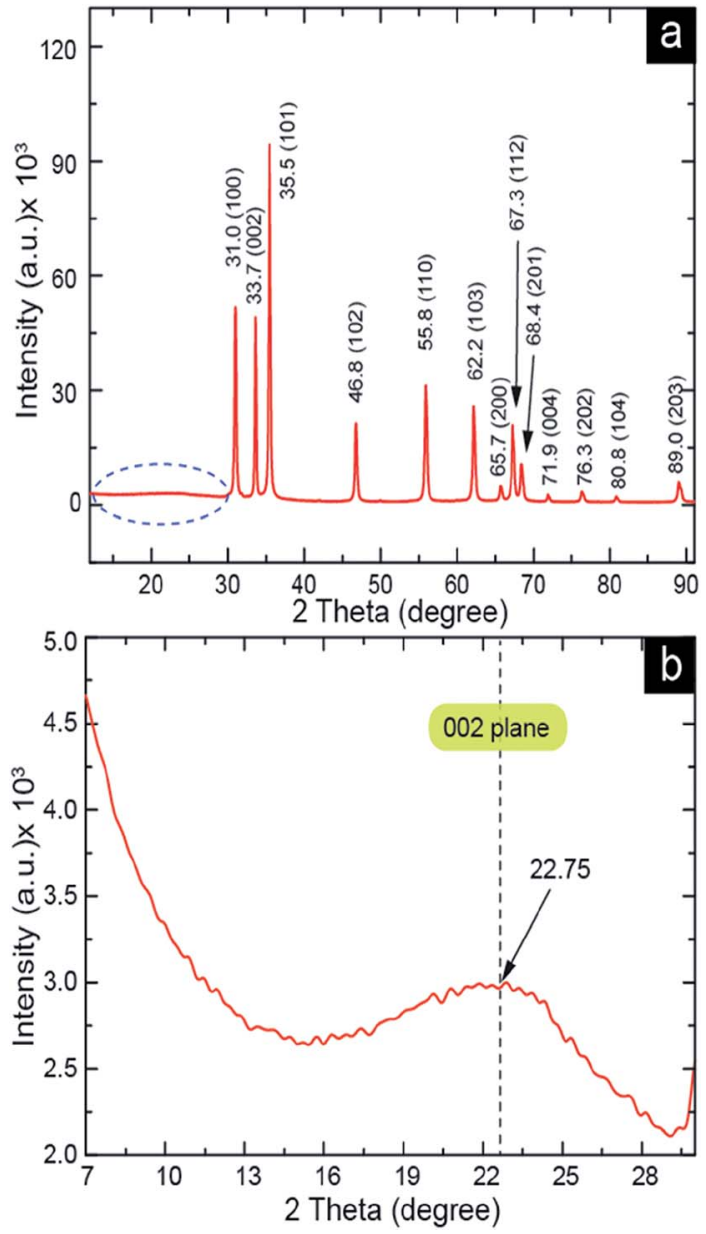

Fig. 5 XRD of ZnO nanorods. (a) ZnO nanorods XRD pattern and (b) high resolution XRD curve of the marked dotted area of (a) was shown here to see the carbon characteristic 002 plane peak.

energies of $288.89 \mathrm{eV}$ and $289.57 \mathrm{eV}$ were created by the interaction of $\mathrm{Zn}$ and $\mathrm{H}$ with the $\mathrm{C}=\mathrm{O}$ system. For this case, $\mathrm{Zn}$ and $\mathrm{H}$ might have interacted with $\mathrm{C}=\mathrm{O}$ and formed $\mathrm{Zn}-$ $\mathrm{O}-\mathrm{C}=\mathrm{O}$ and $\mathrm{H}-\mathrm{O}-\mathrm{C}=\mathrm{O}$ system for $288.89 \mathrm{eV}$ and $289.57 \mathrm{eV}$ peak, respectively. Generally, the chemical-bond binding energy of the carbide type is found in the area $\sim 282-$ $283 \mathrm{eV} .{ }^{55,56}$ Therefore, the peaks at $283.66,283.0$, and $282.0 \mathrm{eV}$ were responsible for the carbide type $(\mathrm{Zn}-\mathrm{C})$ chemical bond. The three peaks at 283.66, 283.0, and $282.0 \mathrm{eV}$ indicated different types of electronegative or oxygen-containing environments near the carbide bond. For instance the $\mathrm{Zn}-\mathrm{C}-\mathrm{Zn}$, $\mathrm{C}-\mathrm{Zn}-\mathrm{C}$, and $\mathrm{O}-\mathrm{Zn}-\mathrm{C}$ carbide systems might have been available. The electronegativity order of these three carbide systems is $\mathrm{Zn}-\mathrm{C}-\mathrm{Zn}<\mathrm{C}-\mathrm{Zn}-\mathrm{C}<\mathrm{O}-\mathrm{Zn}-\mathrm{C}$. Therefore, $\mathrm{Zn}$ has a higher electronegative environment in the $\mathrm{O}-\mathrm{Zn}-\mathrm{C}$ carbide system owing to the oxygen atom. It has a lower and medium electronegative environment in the $\mathrm{Zn}-\mathrm{C}-\mathrm{Zn}$ and $\mathrm{C}-\mathrm{Zn}-\mathrm{C}$ carbide systems, respectively, due to the less and medium electronegative environments compared to oxygen. Thus, the 282.0, 283.0, and $283.6 \mathrm{eV}$ binding energies are associated with the $\mathrm{Zn}-\mathrm{C}-\mathrm{Zn}, \mathrm{C}-\mathrm{Zn}-\mathrm{C}$, and $\mathrm{O}-\mathrm{Zn}-\mathrm{C}$ carbide systems, respectively.
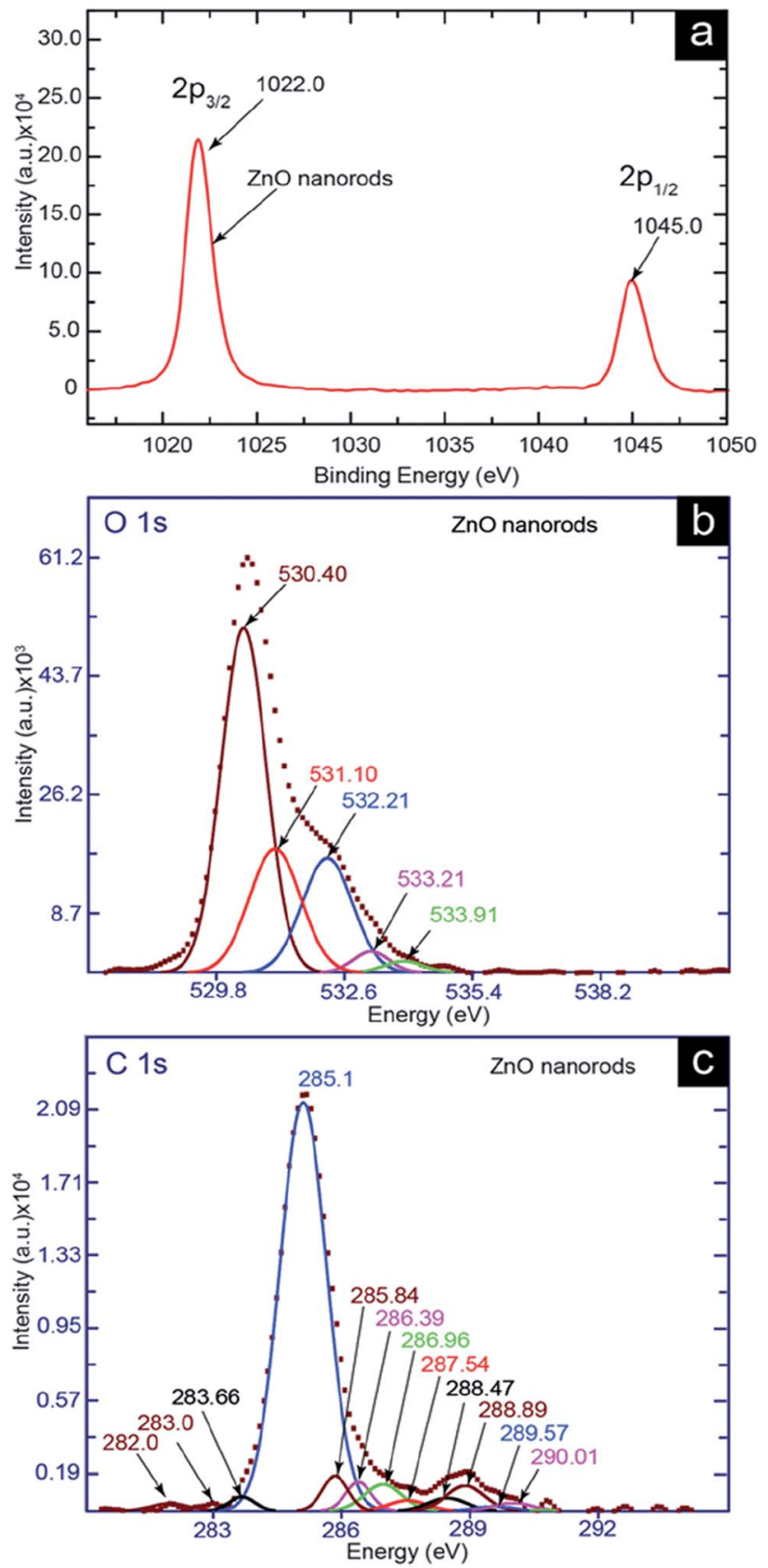

Fig. 6 XPS spectra of $\mathrm{ZnO}$ nanorods. (a) $\mathrm{ZnO} 2 \mathrm{p}_{3 / 2} 2 \mathrm{p}_{1 / 2}$, (b) $\mathrm{ZnO} O 1 \mathrm{~s}$, and (c) C 1s core level XPS spectra.

\subsection{Dispersion concentration and it mechanism for higher dispersion stability}

The prepared $\mathrm{ZnO}$ nanorods (Fig. 7a) were dispersed in ethanol solvent at the rate of $1.2 \mathrm{mg} \mathrm{mL}{ }^{-1}$. Using a bath sonicator, sonication was performed for $5 \mathrm{~min}$ to disperse the $\mathrm{ZnO}$ nanorods. The entire $\mathrm{ZnO}$ nanorods were dispersed in ethanol solution and no sediment appeared within $72 \mathrm{~h}$ (Fig. 7c). Even though no surfactant, ${ }^{20}$ polymer ${ }^{8,21,22}$ phosphate, ${ }^{23}$ inositol hexakisphosphate, ${ }^{24}$ different organic matters, ${ }^{25-27}$ oleic acid, ${ }^{6,28}$ combined polymer and exfoliating agent of zirconium phosphate,${ }^{29}$ ionic materials ${ }^{30}$ and the controlled combined 


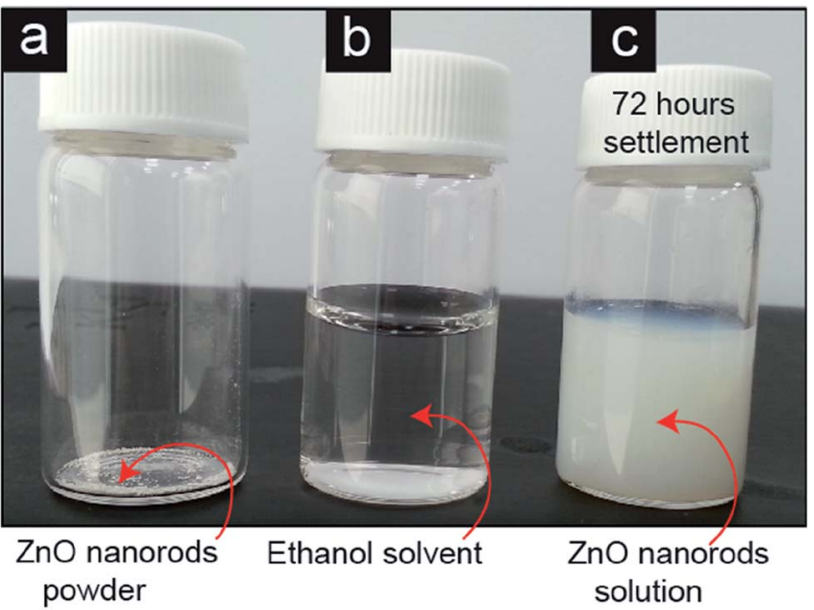

Fig. 7 Dispersion image of $\mathrm{ZnO}$ nanorods (a) ZnO nanorods powder in the vial, (b) ZnO nanorods in ethanol solvent, and (c) dispersed $\mathrm{ZnO}$ nanorods solution in ethanol.

effect ${ }^{31}$ of $\mathrm{pH}$ and ionic strength were utilized to improve the dispersion stability of $\mathrm{ZnO}$ nanorods in the solvent, the $\mathrm{ZnO}$ nanorods exhibited excellent dispersion stability and concentration after only 5 min of sonication. The dispersion concentration is comparatively high (Table S1 $\dagger$ ) than that of other ZnO nanoparticles. ${ }^{3,8,9,20,26,27,29,30,32,33,57,58}$ Therefore, a higher dispersion stability indicates that a good interfacial interaction developed between the $\mathrm{ZnO}$ nanorods and ethanol solvent, which helps to suspend the $\mathrm{ZnO}$ nanorods in the solvent. However, surface modification has significant impact on various properties. ${ }^{4,5}$ Many researchers have identified that the surface modification of nanoparticles by the deposition of other materials enhances the dispersion stability of nanoparticles in liquids. ${ }^{15-31,59}$ Therefore, the functional group of doped carbon, which is created by an in situ process in the $\mathrm{ZnO}$ nanorods through the recrystallization technique, might have increased the dispersion concentration and stability. Based on the XPS analysis, we found that $-\mathrm{COOH},-\mathrm{O}-,-\mathrm{OH},-\mathrm{C}=\mathrm{O}$, etc. are present on the doped carbon surfaces. We proposed that the mechanism of higher dispersion stability of ZnO nanorods shown in Fig. 8. Fig. 8a shows the dispersion of ZnO nanorods in the solvent. The nanorods aggregated after settling (Fig. 8b) in the dispersed solution because there was no barrier layer (Fig. 8c) present at the interface of $\mathrm{ZnO}$ nanorods to prevent aggregation. On the contrary, Fig. 8d shows a good dispersion solution (Fig. 8e) after settlement. The carbon-doped $\mathrm{ZnO}$ nanorods have many functional groups on its surface, which are shown by the different-colored curved lines on the surface of the $\mathrm{ZnO}$ nanorods. These different types of functional groups cause the barrier layers (Fig. 8f) to prevent aggregation. So, $\mathrm{ZnO}$ nanorods are hindered to be close each other for the liquid-phase aggregation. The interaction force at the interface
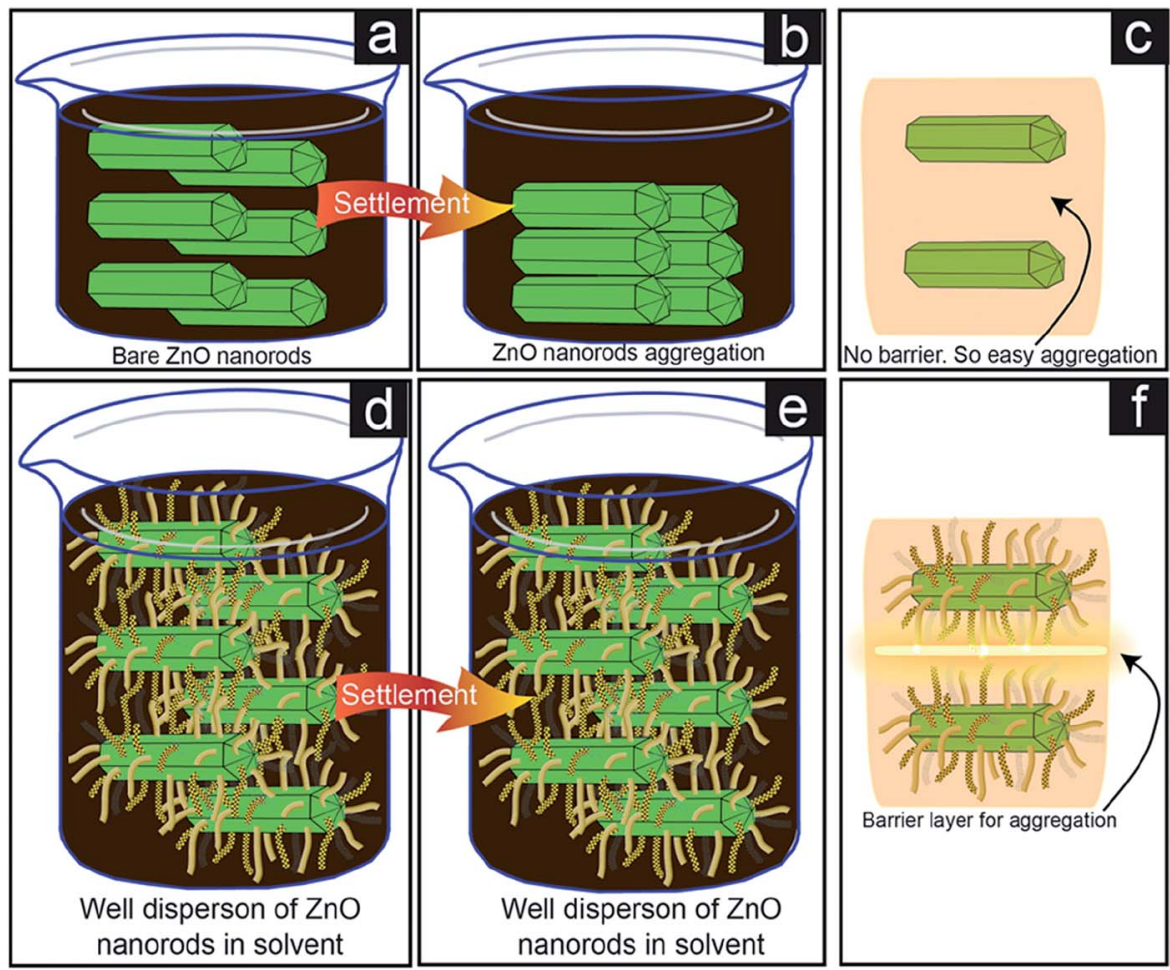

$\underset{\sim}{\sim}$ Functional groups like $-\mathrm{COOH},-\mathrm{OH},>\mathrm{C}=\mathrm{O},-\mathrm{O}-$, etc.

Fig. $8 \mathrm{ZnO}$ nanorods dispersion mechanism. (a) ZnO bare nanorod in ethanol, (b) aggregated $\mathrm{ZnO}$ nanorods after settlement, (c) bare $\mathrm{ZnO}$ nanorods have no barrier layer for stop aggregation, (d) functionalized ZnO nanorods in ethanol solvent, (e) after settlement of ZnO nanorods in ethanol solvents, and ( $\mathrm{f}$ ) the dispersed solution of $\mathrm{ZnO}$ nanorods show good dispersion stability after settlement. 


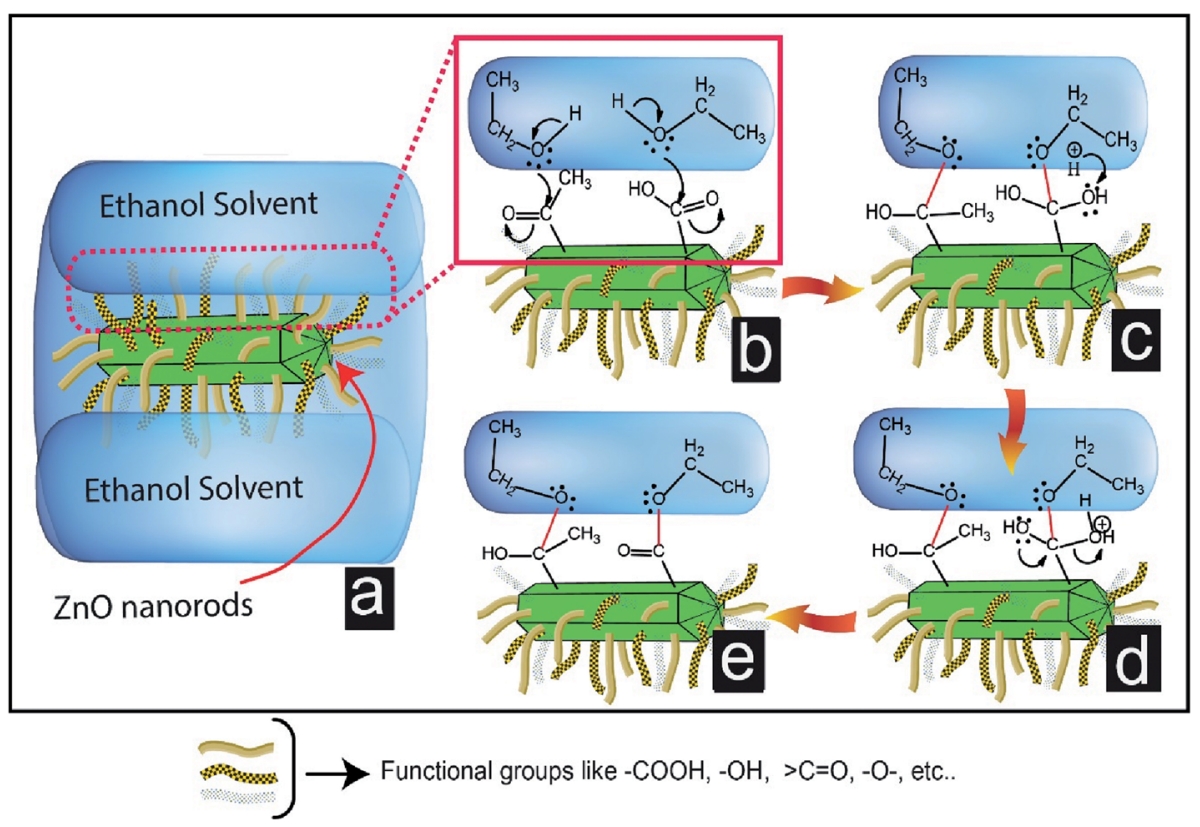

Fig. 9 Interfacial interaction of $\mathrm{ZnO}$ nanorods and ethanol solvents. (a) Interface of the ZnO nanorods and ethanol is shown by dotted marked area, (b) magnifying view of interface of ZnO nanorods and ethanol solvents, (c and d) interaction happening and bond formation (red color bond) with the surface functional groups $(-\mathrm{COOH}$ and $>\mathrm{CO} \cdots)$ of $\mathrm{ZnO}$ nanorods and $\mathrm{OH}$ groups of ethanol, and (e) final bond formation and helping it for floating of $\mathrm{ZnO}$ nanorods in ethanol solvents.

of $\mathrm{ZnO}$ nanorods and solvent through the functional groups of doped carbon may have played important role for higher dispersion concentration. The interfacial interactions through the functional groups are shown in Fig. 9. In this case, new bonds formation are happened (red color bonds) in Fig. 9e. These bonds formation are happened through the reaction steps of Fig. 9c and d. Here, functional groups $-\mathrm{COOH}$ and $>\mathrm{CO}$ reacted with the $-\mathrm{OH}$ groups of ethanol and formed $-\mathrm{O}-$ $\mathrm{C}-$ bonds. Due the formation of these types of bonds with ethanol solvents at the interface, $\mathrm{ZnO}$ nanorods were also floated easily in the solvent. Therefore, two factors such as interfacial barrier layers among the $\mathrm{ZnO}$ nanorods and interfacial interaction between the $\mathrm{ZnO}$ nanorods and ethanol solvent are responsible for the higher dispersion of $\mathrm{ZnO}$ nanorods.

\subsection{Optical properties}

The light absorption property of $\mathrm{ZnO}$ nanorods was measured by UV-visible spectrophotometer. It shows absorption peak at $370 \mathrm{~nm}$ position (Fig. S2 $\dagger$ ). Normally, the absorption intensity was decreased dramatically up to $400 \mathrm{~nm}$. Then, the decreasing rate of light absorption became slower up to $620 \mathrm{~nm}$. After that, decreasing rate of light absorption became near to constant within the range of $620 \mathrm{~nm}$ to $720 \mathrm{~nm}$. Surprisingly, it increases from $720 \mathrm{~nm}$ to $1100 \mathrm{~nm}$. So, this increasing of light absorption in the longer wavelength (720-1100) is very important for the application of ZnO nanorods in visible light driven photocatalysis, water splitting, and for photovoltaic application. The amount of the visible to NIR (400-1100 $\mathrm{nm}$ ) light absorption area (yellow mark part, Fig. S2 $\dagger$ ) was increased significantly due to the increasing of light absorption in longer wavelength instead of decreasing. Probably, the doped carbon inside the $\mathrm{ZnO}$ nanorods played significant role for increasing the light absorption in visible to near IR range..$^{35,60}$

\section{Conclusion}

We synthesized ZnO nanoparticles by a novel recrystallization technique, which is the cheapest and easiest process. The unique recrystallization technique allows a large number of ZnO nanoparticles to be synthesized without utilizing any expensive instrumentation. This is the first report on the preparation of $\mathrm{ZnO}$ nanorods using the recrystallization technique, which allowed for in situ carbon doping in the nanorods without any extra steps, chemicals, or effort. The prepared carbon-doped $\mathrm{ZnO}$ nanoparticles showed excellent dispersion concentration and higher stability than that of the current preparation methods of $\mathrm{ZnO}$ nanoparticles or nanorods. The carbon doping in $\mathrm{ZnO}$ nanorods has different types of functional groups, which are bonded chemically with $\mathrm{Zn}$. These functional groups made the $\mathrm{ZnO}$ nanorods highly dispersible through anchoring them with the solvent in the liquid phase. The mechanism underlying the improved dispersion concentration was demonstrated, and the role of doped carbon in increasing the dispersion concentration and stability was explained.

\section{Conflicts of interest}

The authors declare no competing financial interest. 


\section{Acknowledgements}

This work was supported by the Priority Research Centers Program through the National Research Foundation of Korea (NRF) funded by the Ministry of Education (2014R1A6A1031189).

\section{References}

1 Y. Wu, C. Lim, S. Fu, A. Tok, H. Lau, F. Boey and X. Zeng, Nanotechnology, 2007, 18, 215604.

2 D. T. Wasan and A. D. Nikolov, Nature, 2003, 423, 156.

3 S. Chung, J. Leonard, I. Nettleship, J. Lee, Y. Soong, D. Martello and M. Chyu, Powder Technol., 2009, 194, 75-80.

4 A. C. Balazs, T. Emrick and T. P. Russell, Science, 2006, 314, 1107-1110.

5 L. P. Bauermann, J. Bill and F. Aldinger, J. Phys. Chem. B, 2006, 110, 5182-5185.

6 Y.-S. Fu, X.-W. Du, S. A. Kulinich, J.-S. Qiu, W.-J. Qin, R. Li, J. Sun and J. Liu, J. Am. Chem. Soc., 2007, 129, 16029-16033.

7 D. Vollath, D. Szabo and S. Schlabach, J. Nanopart. Res., 2004, 6, 181-191.

8 H.-M. Xiong, Y. Xu, Q.-G. Ren and Y.-Y. Xia, J. Am. Chem. Soc., 2008, 130, 7522-7523.

9 A. Gankanda, D. M. Cwiertny and V. H. Grassian, J. Phys. Chem. C, 2016, 120, 19195-19203.

10 S. Liu, C. Han, Z.-R. Tang and Y.-J. Xu, Mater. Horiz., 2016, 3, 270-282.

11 S. Liu, Z.-R. Tang, Y. Sun, J. C. Colmenares and Y.-J. Xu, Chem. Soc. Rev., 2015, 44, 5053-5075.

12 B. Weng, S. Liu, Z.-R. Tang and Y.-J. Xu, RSC Adv., 2014, 4, 12685-12700.

13 W. Ostwald, Z. Phys. Chem., 1901, 37, 385.

14 D. V. Talapin, A. L. Rogach, E. V. Shevchenko, A. Kornowski, M. Haase and H. Weller, J. Am. Chem. Soc., 2002, 124, 57825790.

15 M. L. Kahn, T. Cardinal, B. Bousquet, M. Monge, V. Jubera and B. Chaudret, ChemPhysChem, 2006, 7, 2392-2397.

16 D. P. Liu, G. D. Li, Y. Su and J. S. Chen, Angew. Chem., Int. Ed., 2006, 45, 7370-7373.

17 H. M. Xiong, Z. D. Wang, D. P. Liu, J. S. Chen, Y. G. Wang and Y. Y. Xia, Adv. Funct. Mater., 2005, 15, 1751-1756.

18 M. Abdullah, S. Shibamoto and K. Okuyama, Opt. Mater., 2004, 26, 95-100.

19 H. M. Xiong, Z. D. Wang and Y. Y. Xia, Adv. Mater., 2006, 18, 748-751.

20 M. Adil, H. M. Zaid, L. K. Chuan and N. R. A. Latiff, Energy Fuels, 2016, 30, 6169-6177.

21 S. Saliba, C. Valverde Serrano, J. Keilitz, M. L. Kahn, C. Mingotaud, R. Haag and J.-D. Marty, Chem. Mater., 2010, 22, 6301-6309.

22 E. Tang, G. Cheng, X. Ma, X. Pang and Q. Zhao, Appl. Surf. Sci., 2006, 252, 5227-5232.

23 J. Lv, S. Zhang, L. Luo, W. Han, J. Zhang, K. Yang and P. Christie, Environ. Sci. Technol., 2012, 46, 7215-7221.

24 X. Feng, Y. Yan, B. Wan, W. Li, D. P. Jaisi, L. Zheng, J. Zhang and F. Liu, Environ. Sci. Technol., 2016, 50, 5651-5660.
25 C. Jiang, G. R. Aiken and H. Hsu-Kim, Environ. Sci. Technol., 2015, 49, 11476-11484.

26 Y.-H. Peng, Y.-C. Tsai, C.-E. Hsiung, Y.-H. Lin and Y.-h. Shih, J. Hazard. Mater., 2017, 322, 348-356.

27 Y. Zhang, Y. Chen, P. Westerhoff and J. Crittenden, Water Res., 2009, 43, 4249-4257.

28 R. Hong, T. Pan, J. Qian and H. Li, Chem. Eng. J., 2006, 119, 71-81.

29 D. Sun, H.-J. Sue and N. Miyatake, J. Phys. Chem. C, 2008, 112, 16002-16010.

30 C. A. David, J. Galceran, C. Rey-Castro, J. Puy, E. Companys, J. Salvador, J. Monné, R. Wallace and A. Vakourov, J. Phys. Chem. C, 2012, 116, 11758-11767.

31 S.-W. Bian, I. A. Mudunkotuwa, T. Rupasinghe and V. H. Grassian, Langmuir, 2011, 27, 6059-6068.

32 A. A. Keller, H. Wang, D. Zhou, H. S. Lenihan, G. Cherr, B. J. Cardinale, R. Miller and Z. Ji, Environ. Sci. Technol., 2010, 44, 1962-1967.

33 L. Spanhel and M. A. Anderson, J. Am. Chem. Soc., 1991, 113, 2826-2833.

34 M. Hossain, A. Mamun and J. Hahn, J. Phys. Chem. C, 2012, 116, 23153-23159.

35 M. M. Hossain, B.-C. Ku and J. R. Hahn, Appl. Surf. Sci., 2015, 354, 55-65.

36 H. Shima, M. M. Hossain, I. Lee, S. Son and J. R. Hahn, Mater. Chem. Phys., 2017, 185, 73-82.

37 M. Hossain, H. Shima, M. A. Islam, M. Hasan and M. Lee, RSC Adv., 2016, 6, 4683-4694.

38 M. M. Hossain, H. Shima, B.-C. Ku and J. R. Hahn, J. Mater. Sci., 2015, 50, 93-103.

39 M. M. Hossain, O.-K. Park, J. R. Hahn and B.-C. Ku, Mater. Lett., 2014, 123, 90-92.

40 M. M. Hossain, H. Shima, S. Son and J. R. Hahn, RSC Adv., 2016, 6, 71450-71460.

41 M. M. Hossain, H. Shima, M. A. Islam, M. Hasan and M. Lee, J. Phys. Chem. C, 2016, 120, 17670-17682.

42 R. Sato-Berrú, A. Vázquez-Olmos, A. Fernández-Osorio and S. Sotres-Martínez, J. Raman Spectrosc., 2007, 38, 1073-1076.

43 B. Bairamov, A. Heinrich, G. Irmer, V. Toporov and E. Ziegler, Phys. Status Solidi B, 1983, 119, 227-234.

44 D. I. Son, B. W. Kwon, D. H. Park, W.-S. Seo, Y. Yi, B. Angadi, C.-L. Lee and W. K. Choi, Nat. Nanotechnol., 2012, 7, 465.

45 T. C. Damen, S. Porto and B. Tell, Phys. Rev., 1966, 142, 570. 46 C. Arguello, D. L. Rousseau and S. P. d. S. Porto, Phys. Rev., 1969, 181, 1351.

47 M. Koyano, P. QuocBao, L. T. ThanhBinh, L. HongHa, N. NgocLong and S. Ktayama, Phys. Status Solidi A, 2002, 193, 125-131.

48 A. Ferrari and J. Robertson, Phys. Rev. B: Condens. Matter Mater. Phys., 2001, 63, 121405.

49 J. Wang, Z. Wang, B. Huang, Y. Ma, Y. Liu, X. Qin, X. Zhang and Y. Dai, ACS Appl. Mater. Interfaces, 2012, 4, 4024-4030.

50 Y. Lv, L. Yu, H. Huang, Y. Feng, D. Chen and X. Xie, Nanotechnology, 2012, 23, 065402.

51 M. Salavati-Niasari, F. Davar and M. Bazarganipour, Dalton Trans., 2010, 39, 7330-7337. 
52 M. Samadi, H. A. Shivaee, M. Zanetti, A. Pourjavadi and A. Moshfegh, J. Mol. Catal. A: Chem., 2012, 359, 42-48.

53 K. Jayanthi, S. V. Manorama and S. Chawla, J. Phys. D: Appl. Phys., 2013, 46, 325101.

54 C.-C. Teng, C. C. M. Ma, C.-H. Lu, S.-Y. Yang, S.-H. Lee, M.-C. Hsiao, M.-Y. Yen, K.-C. Chiou and T.-M. Lee, Carbon, 2011, 49, 5107-5116.

55 Y.-P. Zhu, M. Li, Y.-L. Liu, T.-Z. Ren and Z.-Y. Yuan, J. Phys. Chem. C, 2014, 118, 10963-10971.
56 X. Zhou, Y. Li, T. Peng, W. Xie and X. Zhao, Mater. Lett., 2009, 63, 1747-1749.

57 W. J. Beek, M. M. Wienk and R. A. Janssen, Adv. Mater., 2004, 16, 1009-1013.

58 C. Pacholski, A. Kornowski and H. Weller, Angew. Chem., Int. Ed., 2002, 41, 1188-1191.

59 H.-M. Xiong, D.-P. Liu, Y.-Y. Xia and J.-S. Chen, Chem. Mater., 2005, 17, 3062-3064.

60 A. F. Khalizov, H. Xue, L. Wang, J. Zheng and R. Zhang, J. Phys. Chem. A, 2009, 113, 1066-1074. 